\title{
AÇÕES PARA MINIMIZAR A FRAGMENTAÇÃO DA EDUCAÇÃO AMBIENTAL EM UMA ESCOLA PÚBLICA PAULISTA
}

Terezinha Marisa Ribeiro de Oliveira ${ }^{1}$ Carmem Lúcia Costa Amaral ${ }^{2}$

Resumo: Este artigo apresenta os resultados de um minicurso de formação continuada de professores sobre Educação Ambiental que teve como objetivo diminuir a fragmentação dessa temática em uma escola pública paulista. $O$ minicurso foi desenvolvido com 35 professores de várias áreas do conhecimento e foi planejado em duas etapas: uma teórica e uma aplicada. $\mathrm{Na}$ teórica foram discutidos textos e na aplicada, os professores planejaram e realizaram ações na escola com seus alunos de forma interdisciplinar. Os resultados evidenciaram que o minicurso contribuiu para a percepção dos professores quanto a importância da Educação Ambiental na sua prática pedagógica e que ela pode transpassar todas as disciplinas.

Palavras-chave: Educação Ambiental, Formação de Professores, ATPCs.

Abstract: This article presents the results of a mini-course of continuing education for teachers on Environmental Education that aimed to reduce the fragmentation of this theme in a public school in São Paulo. The mini-course was developed with 35 teachers from various areas of knowledge and was planned in two stages: theoretical and applied. In the theoretical texts were discussed and in the applied, the teachers planned and carried out actions in the school with their students in an interdisciplinary way. The results showed that the short course contributed to the teachers' perception of the importance of Environmental Education in their pedagogical practice and that it can cross all disciplines.

Keywords: Environmental Education, Teacher Training, ATPCs.

1 Universidade Cruzeiro do Sul. E-mail: terezinha.marisa@gmail.com.

2 Universidade Cruzeiro do Sul. E-mail: carmem.amaral@cruzeirodosul.edu.br. 


\section{Introdução}

O meio ambiente no Brasil, e porque não frisar no mundo, enfrenta desafios frente a falta de uma sensibilização ambiental e como consequência tem-se uma sociedade que não sabe resolver, por exemplo, os problemas do acúmulo de lixo em zonas urbana e rural e principalmente nos rios, mares e oceanos.

Em 2016, durante o Fórum Econômico Mundial, especialistas em Educação Ambiental (EA) previram que em 2050 haverá mais plásticos nos oceanos que peixes (MIWA, 2016). No Brasil, a quantidade de plásticos, tampinhas de refrigerantes e outros resíduos tóxicos produzidos pelos seres humanos são encontrados no estômago de animais marinhos mortos.

O cenário é desanimador. É triste observar as cidades brasileiras rodeadas de lixos de todos os tamanhos e tipos sem visualizar uma política pública que incentive uma mudança desse modelo de sociedade consumista que a cada dia produz mais e mais produtos descartáveis e que promova um debate sobre as suas graves consequências ao futuro do planeta. A população sofre com o aumento de doenças causadas principalmente pela adaptação de muitos parasitas ao meio de vida adotado pela nossa sociedade, provocando constantes epidemias de doenças como Dengue e Febre amarela no país.

Os professores podem mudar esse cenário por meio de um processo de sensibilização da sociedade aos problemas ambientais e assim desenvolver respeito a natureza, com uma postura cidadã comprometida com o futuro do país. Porém, para isso, os professores devem estar preparados para assumir essa responsabilidade perante a sociedade.

Esse processo sem dúvida, passa pela introdução da EA no currículo das escolas públicas e privadas, englobando desde a educação infantil a pósgraduação como enuncia a Política Nacional da Educação Ambiental Brasileira (Lei n 9.795 de 27 de abril de 1999).

Nas escolas brasileiras de Ensino Fundamental Anos Finais e Ensino Médio, em geral, discussões de questões ambientais ocorrem somente em algumas disciplinas como Geografia, Biologia e Ciências, promovendo assim, uma fragmentação no seu conhecimento. Com o objetivo de contribuir para a diminuição dessa fragmentação em uma escola pública de Ensino Fundamental e Médio localizada no estado de São Paulo foi desenvolvido um minicurso de formação continuada em EA com professores de todas as áreas do conhecimento. Esse artigo apresenta o planejamento, a aplicação e os resultados desse minicurso e também tem como objetivo auxiliar outros professores que queiram diminuir essa fragmentação em suas escolas. 


\section{A Educação Ambiental e a formação do professor}

Os problemas ambientais provocados por uma sociedade de consumo, ou seja, uma sociedade que se caracteriza por um consumo exacerbado de bens e serviços, determina uma mudança no modo de pensar e agir dessa sociedade e a escola não pode ficar fora dessa mudança, uma vez que ela é um espaço que, como descrevem Santos e Santos (2016), pode criar condições que levem os estudantes a terem concepções e posturas cidadãs em relação ao meio ambiente.

É necessário que o estudante perceba suas responsabilidades como integrante do meio ambiente, ou seja, ele precisa compreender que faz parte de um todo e deve se interessar e participar na solução de problemas ambientais. Para isso, o papel do professor torna-se imprescindível (VALDUGA; DAL-FARRA, 2011).

Mas, para isso o professor precisa estar preparado, pois como adverte Carvalho (2001) não existem fórmulas prontas para auxiliar o professor no desenvolvimento de práticas educativas relacionadas à temática ambiental. Ainda segundo esse autor, somente a partir de reflexões cuidadosas e escolhas conscientes é que novas perspectivas poderão ser traçadas.

Para traçar essas novas perspectivas descritas por Carvalho (2001), Azanha (2004) descreve que o professor necessita de um espaço para discutir e refletir junto com seus pares sobre a EA. Entretanto, o que se percebe no contexto escolar é que há muitos problemas, como, por exemplo, a carga horária exacerbada que não permite ao professor tempo e espaço para realizar uma discussão sobre a EA com seus pares, embora alguns entendam que o conhecimento dos princípios fundamentais que a sustentam deve ser uma discussão permanente dentro do ambiente escolar.

Além da carga horária do professor, seus conhecimentos sobre EA são insuficientes, pois não foram preparados na sua formação inicial, embora a Lei 9795/99 preveja a obrigatoriedade da inserção dessa temática nos cursos de formação inicial de professores (MELLO; MONTES; LIMA, 2009).

$\mathrm{Na}$ concepção de Lipai, Layrargues e Pedro (2007), a prioridade nos cursos de formação é que se reforce o conteúdo pedagógico e político da EA com embasamentos específicos sobre a legislação e gestão ambiental.

Com os problemas de formação inicial, se faz necessário pensar na formação continuada dos profissionais que estão nas escolas para que consigam desenvolver a EA em suas salas de aulas. Entretanto, em que momento os professores das mais diferentes áreas podem estar executando uma formação continuada em EA? Para nós, esse momento é durante a reunião de Atividades de Trabalho Pedagógico Coletivo (ATPCs), uma vez que nessa reunião os professores e a equipe gestora se encontram para discutir questões do cotidiano escolar e de formação. De acordo com Santos (2001), muitos projetos têm utilizado os espaços das ATPCs das unidades escolares 
para a capacitação de professores em EA, pois essas atividades abrangem todos os profissionais no âmbito escolar como descrito acima.

Levando em consideração que a EA é um ato político-pedagógico, Mendonça (2007) considera que na formação continuada, a EA faça parte da gestão escolar, do Projeto Político Pedagógico (PPP) da escola, pois ao incidir sobre o individual e o coletivo a escola se compromete com uma mudança em relação as questões ambientais. Para esse autor, a EA também deve estar inserida no contexto da sua transversalidade como forma de se opor a fragmentação do currículo.

A transversalidade é entendida, de acordo com a Resolução nํ4, de 13 de julho de 2010, que define as Diretrizes Curriculares Nacionais Gerais para a Educação Básica como "uma forma de organizar o trabalho didático pedagógico em que temas e eixos temáticos são integrados às disciplinas e às áreas ditas convencionais, de forma a estarem presentes em todas elas" (BRASIL, 2010).

Além da transversalidade, a EA deve ser trabalhada de forma contínua, sistemática, abrangente e deve estar relacionada com questões da atualidade (BRASIL, 1998). Entretanto, para isso é importante que o professor esteja preparado e que essa preparação, como descreve Faht (2011) ocorra a partir de cursos de formação continuada, em encontros de capacitação.

Ao propor cursos de capacitação para a formação de professores em EA, é preciso entender, como pontua Medina (2001), este como um sujeito que ao aprender sobre EA, deve se envolver na melhoria da qualidade da escola com um estudo contínuo e desenvolver projetos coletivamente.

A escola é o locus ideal para que os professores tenham acesso a uma formação continuada em EA. Cabe a equipe gestora identificar o que seus docentes necessitam para que o trabalho com seu discente alcance os objetivos traçados.

\section{Aspectos metodológicos}

Participaram do curso de formação continuada 35 professores das áreas de Códigos de Linguagens (Língua Portuguêsa, Inglês, Arte e Educação Física), Ciências da Natureza (Ciências, Química, Física e Biologia), Ciências Humanas (História, Geografia, Filosofia e Sociologia) e Matemática. Esses professores lecionavam no Ensino Fundamental e Médio em uma escola estadual localizada na cidade de São Paulo.

O minicurso contou com seis encontros nas reuniões de ATPC. O planejamento desses encontros está apresentado no Quadro 1. Os docentes foram identificados pela letra $P$ seguida de um número $\left(P_{1}, P_{2}, \ldots . P_{35}\right)$. 
Quadro 1: Atividades desenvolvidas nos encontros.

\begin{tabular}{|c|l|}
\hline Encontros & \multicolumn{1}{c|}{ Atividades desenvolvidas } \\
\hline $\mathbf{1}$ & Discussão do anexo III dos PCN. \\
\hline $\mathbf{2}$ & Lei no 9.795 de 27 de abril de 1999 que dispõe sobre a EA. \\
\hline $\mathbf{3}$ & $\begin{array}{l}\text { Artigo Sorrentino (2006) "De Tibilisi a Thessoloníki: a Educação Ambiental } \\
\text { no Brasil". }\end{array}$ \\
\hline $\mathbf{4}$ & Discussão da carta da terra. \\
\hline $\mathbf{5}$ & $\begin{array}{l}\text { Planejamento de ações a serem desenvolvidas na escola de forma } \\
\text { interdisciplinar }\end{array}$ \\
\hline $\mathbf{6}$ & Discussão das ações desenvolvidas pelos docentes com seus alunos. \\
\hline
\end{tabular}

Fonte: Autoras.

\section{Resultados dos Minicursos e ações dos Professores}

No primeiro encontro foi apresentado o Anexo III dos PCN (1997), pois considerou-se importante que os docentes tivessem como referência as noções centrais sobre EA discutidas nesse anexo. Estas noções envolveram conceitos de Meio Ambiente, de Sustentabilidade e Diversidade.

Antes, porém foi questionado aos docentes se eles conheciam esse anexo. A resposta foi negativa. Assim, surgiram vários comentários e argumentou-se que para tratar a EA nas aulas é importante conhecer o arcabouço teórico, e assim construir um embasamento para saber argumentar com os alunos sobre o tema.

A docente P25 comentou:

O ENEM já abordou essa temática da EA e os alunos, em geral, não têm um embasamento teórico para desenvolver a redação porque eles não conseguem fazer um link com o que ele aprendeu nas outras disciplinas com a matéria da Língua Portuguesa. Esse link é importantíssimo para eles colocarem na argumentação. Eles até fazem uma proposta de uma tese, mas na hora de argumentar, de abordar, eles não conseguem associar, então seria interessante fazer isso.

Após a fala da docente P25, deu-se início a discussão de alguns conceitos do tópico meio ambiente presentes no Anexo III. Entre esses conceitos estão: fatores abióticos (sem vida) e seres bióticos (vivos), sua interação, troca de energia, transformações que sofrem e as causam dessa transformação na biosfera. Em seguida foram tratados a relação do meio ambiente e seus elementos (Elementos naturais do meio ambiente e os manipulados pelos seres humanos, fatores físicos e sociais, formas de intervenção no meio ambiente, proteção, preservação, conservação, recuperação e degradação). 
Quanto à sustentabilidade, o texto discute que não há como garanti-la a longo prazo, devido ao não conhecimento futuro e a imprevisibilidade de muitos fatores. Assim, a escola deve estar ciente desses fatores para contribuir com o processo de monitoramento das decisões, avaliação e redirecionamento de ações dentro do que exige o princípio de sustentabilidade.

Um fato interessante aconteceu quando ao ler um dos parágrafos do anexo III, que comentava sobre a EA ser um assunto relativamente novo, os docentes ficaram estarrecidos com o tempo transcorrido desde a publicação dos PCNs e a inevitável comparação com a evolução que o tema alcançou dentro da escola. São mais de 20 anos, porém nenhum docente sequer leu ou conhece totalmente os assuntos tratados nos PCN. Do mesmo modo, a discussão sobre a Base Nacional Comum Curricular (BNCC) que foi aprovada em 2017 não está incorporada ao dia a dia escolar.

A docente P13 acrescentou:

Não se discute com os professores porque não é interessante que crie um sujeito questionador, crítico. É importante que os professores estejam engajados e a par das mudanças que acontecem. Por isso a importância que sempre ocorra esse tipo de debate nas reuniões de ATPCs.

A discussão terminou com os docentes comentando a importância que tem a EA dentro da escola, pois pode causar conflitos entre os funcionários da limpeza e entre professores e que há todo um contexto envolvido com diversas relações que pode comprometer a interação com os outros. Comentaram, também, como o tema está fragmentado dentro da escola.

O segundo encontro teve como discussão a Lei $n^{\circ} 9.795$ de 27 de abril de 1999, que dispõe sobre a EA e institui a Política Nacional de Educação Ambiental. O objetivo principal deste encontro foi mostrar aos docentes a importância de conhecer e discutir este instrumento legal e normativo.

Em todos os encontros procurou-se diversificar as formas de apresentação dos conteúdos trabalhados. Para este encontro foi escolhido o aplicativo Prezi como recurso tecnológico, para que todos conhecessem novas formas de apresentação de trabalhos.

Antes de iniciar a reunião, foi questionado se conheciam o aplicativo. Somente um docente respondeu que sim e explicou que a primeira vez que entrou em contato com o aplicativo foi por meio de um aluno. Esta resposta evidencia que quanto as tecnologias o aluno está mais à frente que o professor. Como descrevem Cunha, Cunha e Cunha (2015) o professor tem que se adequar às tecnologias porque é uma maneira de motivar a geração $Y$ na escola. A Geração Y são os nascidos a partir do período de 1990.

Para Pereira e Freitas (2009, p.23) "o professor precisa conhecer e estar consciente de que o uso das tecnologias tem reflexos na sua prática 
pedagógica e nos processos de aprendizagem, contribuindo para a construção de conhecimentos".

Sobre a Lei $n^{\circ} 9.795$ de 27 de abril de 1999 que dispõe sobre a EA, os professores, ao serem indagados se tinham conhecimento desse instrumento normativo, apenas uma professora indicou que sabia da existência dela, porém não conhecia o teor.

O desconhecimento total da Lei 9795/99, mesmo com docentes das diversas disciplinas presentes no ATPC, foi determinante para que percebessem a importância de estar participando de um curso de formação em EA, pois aparentemente pode-se pensar que todos têm o domínio dos assuntos trabalhados em EA, o que vem se provando o contrário.

Durante a discussão os docentes mostraram-se surpresos ao saber que todas as disciplinas deveriam trabalhar EA e não somente as disciplinas clássicas que sempre estão ligadas ao contexto. Nesse mesmo aspecto, a formação continuada para os professores em sua área de atuação também chamou a atenção dos professores.

$\mathrm{O}$ artigo 10 da referida Lei, descreve no seu primeiro parágrafo que a EA não precisa ser implementada como uma disciplina específica no currículo. Entretanto, $\mathrm{P}_{33}$ comentou que na graduação cursou uma disciplina específica de EA. Este comentário abriu uma discussão no grupo e mais adiante, no segundo parágrafo do mesmo artigo, está escrito que a criação de uma disciplina específica é facultativa para cursos de pós-graduação, extensão e nas áreas voltadas ao aspecto metodológico da EA.

A criação de uma disciplina específica para EA faz com que sejam fragmentados os conteúdos escolares, pois como descreve Furtado (2009 apud ADAMS, 2012), a EA tem um caráter transversal. Além da transversalidade, essa Lei também argumenta que a EA deve ser contínua, sistemática e abrangente.

No terceiro encontro foi apresentado o texto do Sorrentino (2006), que discute as quatros correntes: (conservacionista, educação ao ar livre, gestão ambiental e economia ecológica) e os diversos tipos de projetos educacionais desenvolvidos no Brasil. Este autor agrupou estes diferentes tipos de projetos em quatro grupos: biológicos, espirituais/culturais, políticos e econômicos.

Os projetos biológicos, segundo Sorrentino (2006), discutem a importância de conservar a biodiversidade e o clima do planeta para encontrar as causas da degradação da natureza, sendo o homem parte integrante desse sistema que tem como meta a conservação e utilização dos recursos naturais.

Com relação aos projetos espirituais/culturais discute a relação dos seres humanos com o Universo, com a intenção de resgatar valores ligados ao sentimento (amor, paz, felicidade...etc.) e as tradições que possibilitem uma nova organização espacial e temporal como um todo. 
Os projetos do tipo político discutem o papel de cada um na sociedade, de forma democrática, estimulando as discussões e a participação popular nas decisões políticas, em igualdade de condições, enquanto os projetos econômicos discutem como melhorar a qualidade de vida com geração de empregos em atividades ambientais, sem destruir o meio ambiente, caminhando para uma autogestão de trabalho, recursos e mesmo dos seus conhecimentos.

Após a apresentação e discussão destes tipos de projetos foi questionado qual é o projeto desenvolvido em nossa escola. Alguns docentes responderam que seria o biológico, porém com a discussão chegou-se à conclusão de que a escola não tem um projeto de EA que temos algumas disciplinas que falam de EA, cada uma em seu contexto. Essa fala dos docentes mostra a fragmentação da EA na escola e a necessidade de desenvolver projetos de EA envolvendo todas as disciplinas, de forma transversal, como sugere Furtado (2009 apud ADAMS, 2012).

$\mathrm{O} \mathrm{P}_{24}$ acrescenta que:

A EA deveria ser trabalhada na escola partindo do micro(local) para se chegar ao macro (mundo). Para ele o que acontece na escola é justamente o contrário e, por isso, a escola não tem conseguido alcançar os objetivos da EA e, como consequência, as propostas pontuais de alguns docentes não conseguem fazer com que o aluno adote a EA como parte de sua responsabilidade enquanto cidadão.

Um exemplo citado foi o episódio que ocorreu ao final do ano letivo de 2017. Os alunos ao saírem da escola, subiram em uma passarela e jogaram apostilas e cadernos em todas as ruas que davam acesso aos bairros, podendo causar um acidente. Ao ver esta cena, a comunidade que está olhando para dentro da escola se pergunta: que tipo de educação nós estamos executando dentro da escola? acredita-se que para essa comunidade, a escola não está cumprindo seu papel de formação cidadã.

Com o intuito de acabar com a chuva de papel os docentes sugeriram recolher os materiais que os alunos não utilizaram e que podiam ser doados para reciclagem ao final do semestre. Além de conversar com os alunos sobre as atitudes que podem acarretar grandes transtornos ao próximo.

O $\mathrm{P}_{24}$ complementou:

Eu acho que a gente tem que pensar na limpeza das salas, na organização do ambiente, porque isso muda o comportamento das pessoas. As vezes a gente reclama que os alunos estão muito agitados, mas esquecemos que a limpeza e a organização no contexto da sala de aula são muito importante. 
Sobre o assunto outros docentes argumentaram que a questão da limpeza causa muitos problemas dentro da escola, até mesmo de relacionamento entre os funcionários, pois os mesmos reclamam que não são respeitados no seu trabalho, como deveriam; que a educação no contexto geral, seja ambiental ou pedagógico, passa por esse respeito ao trabalho do outro.

Essas falas mostram que a escola não desenvolve o papel que the cabe e acaba por desfigurar a EA, que fica relegada a um segundo plano. A escola precisa parar para rever suas ações e não apenas para uma mudança de comportamento, mas em uma reflexão de atitudes que gerem uma consciência crítica.

Nesse instante, a $P_{23}$ que já foi por muitos anos coordenadora, descreve trechos das suas conversas com os alunos: "Você rabisca a mesa da sua casa, não rabisca e porque aqui rabisca, porque aqui joga papel no chão".

A $\mathrm{P}_{29}$ responde: "Porque aqui tem gente que limpa". A $\mathrm{P}_{23}$ retoma a fala, "mas, é isso que eu falo. Não pode ter um comportamento em casa e na escola ter um outro. Na vida somos um só".

pais:

A P25 comentou outro episódio que aconteceu em uma reunião de

Alguns anos atrás, a direção da escola pediu para conversar na reunião de pais sobre a limpeza da sala de aula, para que eles conservassem com seus filhos. E eu vi uma mãe ali na frente comendo salgadinho e quando acabou de comer jogou a embalagem no chão. Como você vai falar para a mãe desse aluno para educar o filho dela se ela mesma não tem essa educação? Um irmão de um aluno falou que isso é normal o brasileiro joga tudo no chão mesmo, brasileiro é assim, ele ainda justificou o lixo que a mãe jogou no chão.

Para o docente $P_{32}$ o brasileiro só toma consciência quando dói no bolso, o aluno rasga o caderno, joga folha no chão, quebra os lápis porque ele sabe que vai ganhar outro. A partir do momento que tiver que comprar um lápis, um caderno ele terá outra atitude.

O ATPC terminou com os agradecimentos de todos pela participação. Alguns docentes comentaram da sua importância, pois de acordo com eles, no espaço escolar é muito difícil parar para ouvir os colegas e assim discutir ações que realmente acrescente ao ambiente escolar uma integração entre as disciplinas.

No encontro 4 o texto discutido foi a Carta da Terra. Novamente somente uma professora o conhecia, pois trabalhou no Zoológico de Sorocaba (cidade de São Paulo). Após essa etapa os docentes assistiram um vídeo sobre a Carta da Terra retirado do site do Ministério do Meio Ambiente, com uma duração em torno de 24 minutos. 
Ao longo da apresentação, o vídeo era parado para discussão. Por exemplo, em um trecho a carta cita que "é importante honrar e apoiar os jovens das nossas comunidades, habilitando-os a cumprir seu papel essencial na criação de sociedades sustentáveis". Todos falaram o quanto o professor é essencial na vida dos jovens que estão em formação.

Outros comentários foram:

A carta da Terra não é uma coisa pequena, ela é muito grande e nós somos um universo muito grande na vida de muitos alunos porque eles nos tomam como referência. Ao trabalharmos o meio ambiente, falamos sobre um contexto abrangente, porque tudo está interligado com o social e com o econômico. Você vê que é uma carta muito profunda para a humanidade, porque não fala do planeta, mas de todos os seres vivos. Ela mostra todos aqueles animais que muitas vezes a gente não dá valor, mas que é importante para o equilíbrio da natureza. Essa carta é um alerta para a humanidade, ela é sensacional (Supervisora $S_{1}$ ).

$\left(\mathrm{P}_{23}\right)$.

Se formos analisar, já se passaram 18 anos dessa carta e nada mudou

Sobre este último comentário a $P_{19}$ argumenta que o problema é do sistema capitalista que vivemos, que só se interessa pelo financeiro.

Este encontro teve uma participação intensa dos docentes, todos estavam concentrados no assunto apresentado e, no final, mostraram-se surpresos por um documento tão importante como este e que demandou esforço de vários países, ser pouco conhecido e trabalhado com os alunos. No final deste encontro, os docentes reforçaram a importância de a EA fazer parte do contexto escolar, e que para isso era importante sua incorporação no PPP.

No encontro 5 os docentes planejaram ações que seriam desenvolvidas na escola de forma interdisciplinar, sem modificar a dinâmica das atividades programadas pela Secretaria do Estado da Educação.

A estratégia proposta para compor o projeto de ação envolvendo a EA foi partir das habilidades que estavam em defasagem em Matemática e Língua Portuguesa. Essas habilidades foram detectadas a partir da aplicação da Avaliação de Aprendizagem em Processo (AAP), uma prova elaborada pela Coordenadoria de Informação, Monitoramento e Avaliação Educacional (CGEB), que é aplicada bimestralmente.

A AAP tem como objetivos diagnosticar a aprendizagem de cada aluno, de cada turma e, consequentemente, o desempenho da escola no processo de ensino e aprendizagem e auxiliar os professores em uma recuperação contínua dos conteúdos. Para auxiliar o professor na recuperação contínua, em 2016, a 
Coordenadoria de Gestão da Educação Básica elaborou a Matriz de Avaliação Processual, que indica os conteúdos, as competências e habilidades que devem ser desenvolvidas no âmbito escolar (OLIVEIRA, 2018).

Para auxiliar na recuperação contínua dos estudantes, utilizando como tema transversal a EA, os docentes foram divididos em dois grupos. O primeiro propôs estratégias de ensino para desenvolver as habilidades em defasagem na área de Língua Portuguesa. Os docentes desse grupo eram das áreas de Linguagens e Códigos e Ciências Humanas e suas tecnologias. O segundo grupo propôs também estratégias para o desenvolvimento de habilidades da área de Matemática. Os docentes desse grupo eram das áreas de Matemática e suas tecnologias e Ciências da Natureza e suas tecnologias.

As habilidades em defasagens em Língua Portuguesa observadas a partir do AAP foram: identificar recursos semânticos expressivos (antítese, personificação, metáfora, metonímia) em seguimentos de um poema, estudo do gênero textual injuntivo/prescritivo e leitura e interpretação de textos. Para Matemática, as habilidades identificadas foram: realizar operações com números racionais com o uso de números decimais; o cálculo da média aritmética e da porcentagem e o emprego da notação científica.

As estratégias propostas para desenvolver as ações de EA utilizando essas habilidades em defasagens foram agrupadas para a Educação Básica (Anos Finais do Ensino Fundamental) e o Ensino Médio. Essas estratégias foram: Coleta e análise de dados sobre o racionamento do uso de agua; pegada ecológica a partir de análise de vídeo; elaboração de um projeto sobre a reciclagem de pilhas; confecção de cartazes e pesquisa sobre o EA; pesquisa sobre o problema das sacolas plásticas; o crescimento da fabricação dos smartphones e suas relações com a problemática da exploração da população do Congo; utilização de aplicativos para criar as apresentações das atividades propostas; as fontes e as formas de energia, transformações ambientais e ciclos da natureza; análise e interpretação de informações geográficas expressas de diversas maneiras; leitura reflexiva sobre o nosso lixo.

\section{Ações desenvolvidas com alunos do Ensino Fundamental Anos Finais}

\section{Atividade 1}

Em uma das ações sobre o trabalho com EA, os alunos realizaram uma pesquisa na sala de informática sobre a reciclagem de pilhas e baterias, a fim de que entendessem o perigo de joga-las no lixo comum. Para surpresa dos docentes, os alunos dos $6^{\circ}$ e $7^{\circ}$ Anos, advindos da rede municipal, estavam habituados a realizar a coleta seletiva não só das pilhas e baterias, mas também de lâmpadas, pois em suas antigas escolas havia containers para a coleta desses materiais para serem levados à reciclagem. Isso demonstra a fragmentação do tema nas redes municipal e estadual, mostrando estarem desconectadas do contexto socioambiental, pois ao que se pode notar, não 
existe uma continuidade no trabalho dos Anos Iniciais do Ensino Fundamental com os Anos Finais.

Esta ação teve como objetivos: sensibilizar os alunos quanto a importância de seu papel no mundo e entender que pequenas ações, como coleta de pilhas e baterias, podem contribuir para que o planeta se torne melhor, além de torná-los participantes, ativos e críticos do sistema que hoje estamos inseridos. Para os docentes, a participação dos alunos foi avaliada como positiva pelo envolvimento e comentários realizados durante as aulas.

Com o respaldo dos alunos, os docentes sugeriram que esse tipo de ação se torne definitivo dentro da escola e que esta seja estendida para as reuniões de pais, que ocorrem bimestralmente, e para a comunidade com a divulgação no comércio local.

\section{Atividade 2}

A proposta foi utilizar os textos de diversos gêneros que contemplassem reflexões sobre a importância do meio ambiente para a vida no planeta, sua preservação, medidas governamentais contraditórias, influência do sistema capitalista na ação de preservação.

As atividades pedagógicas tiveram início com uma pesquisa individual sobre as figuras de linguagem no minimanual de gramática e do posterior registro de seus resultados no caderno de cada aluno. Na segunda etapa, os docentes desenvolveram uma aula expositiva dialogada com o intuito de realizar aprofundamentos e sondagens sobre o processo de aprendizagem dos alunos.

A professora de Língua Portuguesa $\left(\mathrm{P}_{6}\right)$ desenvolveu com seus alunos um jogo com situações problemas sobre desmatamento, queimadas e a problemática da água no planeta. Para isso ela construiu fichas e uma trilha de bambolês. Cada um tinha uma questão para identificar a figura de linguagem presente em uma situação problema propostas. Os alunos iam jogando um dado nessa trilha e respondiam as questões referentes a cada bambolê da trilha.

A professora $\mathrm{P}_{6}$ descreveu que as atividades desenvolvidas alcançaram os objetivos desejados e planejados com uma surpreendente interação entre os alunos e uma participação intensa de todos os envolvidos.

\section{Atividade 3}

A terceira atividade desenvolvida pelos docentes de Ciências foi a Pegada ecológica que é um indicador que mostra quanta área produtiva de terra é utilizada para produzir o que se usa e se consume. Ela permite comparar diferentes padrões de consumo e verificar se estão dentro da capacidade ecológica do planeta. Essa atividade teve dois objetivos: calcular o quanto consumimos de recursos naturais para que os alunos entendessem que 
o nosso estilo de vida faz com que utilizemos cada vez mais os recursos naturais do planeta em um ritmo mais acelerado do que a sua capacidade de reposição; reavaliar hábitos e comportamentos familiares ou individuais que possam comprometer o equilíbrio ecológico do planeta Terra.

Para iniciar esta atividade, a professora $\mathrm{P}_{26}$ trouxe um vídeo do material distribuído pela Secretaria de Educação de São Paulo para o EJA (Educação de Jovens e Adultos). Este vídeo trata o processo de consumismo em quatro áreas: moradia, transporte, materiais eletrônicos e lixo e explica o que é uma pegada ecológica. O vídeo mostra o cotidiano de duas pessoas, uma extremamente consumista e a outra nada consumista, cada um calculando a sua pegada ecológica. Depois de assistirem o filme, a atividade seguinte foi uma roda de conversa para discutir as ações dos personagens do filme estabelecendo relações com as ações e atitudes do cotidiano dos alunos. Esta atividade teve a duração de 2 aulas.

$\mathrm{Na}$ aula seguinte, da mesma semana, os alunos responderam um teste que foi elaborado pela Redefining Progress (www.myfootprint.org), pelo qual se pode calcular a Pegada Ecológica. Assim, cada aluno calculou a sua pegada, analisou seus resultados e comparou com as dos seus colegas.

Ao término das atividades propostas, os alunos realizaram uma autoavaliação dos seus hábitos de consumo e de seus familiares para tentar diminuir a sua pegada ecológica no planeta e elaborar uma lista de atitudes que possam reduzir os seus impactos sobre o planeta.

Para os docentes a atividade foi muito proveitosa, pois os alunos gostaram e acharam interessante avaliarem o impacto de suas ações sobre o planeta, embora tenham consciência da necessidade de terem mais atitudes e ações sustentáveis. Um dos docentes comentou:

Essa pegada é uma espécie de medição da utilização dos recursos naturais e está relacionada diretamente com os hábitos de vida de uma população. Após a essa sensibilização os alunos puderam registrar através de testes, o quanto estão fazendo gasto dos recursos naturais, isto gerou neles uma preocupação muito significativa quanto a sua marca, e o que eles podem fazer para reverter esta situação. Pudemos perceber que muitos dos discentes não tinham conhecimento deste cálculo, e que através de pequenos gestos de sensibilização pode-se rever grandes coisas. O projeto foi de grande valia, pois todas séries tiveram participação ativa, na questão dialogada, realização de teste e construção de gráficos. Atuar como um centro de informação e formação ambiental em nossa comunidade está sendo um espaço de encontro, reflexão e construção da ação socioambiental, por meio da realização de ações educativas como o próprio projeto, palestras, oficinas, eventos, encontros, reuniões, campanhas, exposições, mostras etc. Tudo isto gera no cidadão um ato de responsabilidades e reflexão para as futuras gerações viventes na biosfera. 


\section{Atividade 4}

Esta atividade teve como objetivos resolver situações problemas envolvendo adição, subtração, multiplicação e divisão de números racionais; resolver situações problemas envolvendo a comparação de grandezas representadas por números racionais com foco na EA.

Em casa os alunos coletaram a água do chuveiro em garrafas PET de $500 \mathrm{~mL}$ por 10 segundos e trouxeram para a aula. $\mathrm{O}$ objetivo dessa atividade foi calcular a quantidade da vazão de cada chuveiro. Também foi cronometrado o tempo de todos os banhos do dia em cada residência. A intenção era a transformação desses números em números racionais e assim calcular a quantidade de água utilizada em sua residência somente com banhos. Como pode ser notado, esta atividade foi uma continuação da atividade 3 , pois utilizou os conceitos do vídeo sobre a Pegada Ecológica.

$\mathrm{Na}$ sala de aula, com os dados do consumo de água dos banhos de cada aluno, os resultados foram comparados com os dados de consumo estabelecido pela ONU que determina o aceitável para cada indivíduo. Após essa etapa os alunos calcularam o consumo de água em banhos de toda a família.

A água que foi coletada pelos alunos em casa no chuveiro, depois de calculado o volume, foi utilizada para regar o jardim da escola, e os recipientes que armazenaram a água foram enviados para a coleta seletiva.

Com os resultados obtidos sobre o consumo diário de água da residência de cada aluno, a tarefa foi fazer uma reflexão respondendo ao questionamento: o que cada um pode fazer para diminuir este resultado e, assim diminuir a pegada que deixa no planeta Terra?

\section{Atividade 5}

O tema Consenso e não desperdício de água, foi escolhido para desenvolver a habilidade de realizar operações com números racionais, o uso de números decimais, o cálculo da média aritmética, porcentagem e o emprego da notação científica. Esta atividade teve o mesmo contexto da anterior, a diferença foi a estratégia utilizada pela $P_{16}$ que solicitou aos alunos que realizassem um levantamento em suas casas sobre o consumo de água a partir das contas de água. Com esses dados, os estudantes calcularam na sala de aula qual era o consumo médio de água por dia para as mais diversas atividades (consumo humano, higiene bucal, banho, descarga, entre outros).

Posteriormente os alunos começaram a calcular a média de consumo da classe e iniciaram a construção de gráficos e cartazes. Os alunos também realizaram uma pesquisa sobre o consumo de água em diferentes países e nas diferentes regiões do Brasil. Todos os dados foram utilizados para a análise e construção de gráficos. 
O processo de ensino e aprendizagem desenvolvido foi avaliado pela professora $\mathrm{P}_{9}$ a partir dos cartazes confeccionados pelos alunos e pelo acompanhamento na execução dos cálculos e da organização das informações coletadas. A atividade foi considerada proveitosa e importante pelos alunos.

\section{Atividade 6}

Para desenvolver atividades de operações com números racionais, utilizando a transformação de números em notação científica e a construção de gráficos, foram escolhidos dois textos, um sobre a produção de celulares e outro sobre descarte de sacolas plásticas.

Após o debate dos textos, os alunos ficaram impressionados ao saber que os celulares ao serem produzidos em larga escala pelas gigantes mundiais nesse setor, tem um grande impacto ambiental e social, pois o coltan, um dos materiais utilizados por esse setor, tem forte influência na escravização de crianças e em guerras no país africano Congo.

Os alunos, divididos em grupos, utilizaram as informações disponibilizadas no material para construir gráficos, realizar transformações numéricas para a notação cientifica e operações utilizando números decimais.

Para contemplar as atividades foi sugerido que os alunos apresentassem seus resultados utilizando o aplicativo Lensoo Create. Essa escolha se deve ao fato do uso desse aplicativo permiti ao docente analisar o processo de aprendizagem, pois é uma estratégia diferenciada que pode ajudar no interesse do aluno, além de possibilitar uma interação com a tecnologia e a reflexão sobre o uso e os descartes dos smatphones.

O aplicativo Lensoo Create pode ser usado em dispositivos móveis, tanto em tablet e iPad ou smartphones, transformando-se em uma lousa digital na qual o aluno pode escrever, inserir imagens, desenhar e gravar áudio (OLIVEIRA, 2018).

De acordo com professora a avaliação dessa atividade foi positiva e houve participação e mobilização dos alunos. Esse estímulo à aprendizagem favorece o desenvolvimento da habilidade em questão e o ensino do tema a partir da decisão docente de incentivar a aprendizagem por meio da inclusão de recurso tecnológico, juntamente com temas transversais como a EA, facilitou a desmistificação e a interação da matemática.

\section{Atividades 7 e 8}

A atividade 7 foi desenvolvida pelos docentes de geografia, com os objetivos de incentivar os alunos a interpretar mapas, fluxogramas, gráficos; elaborar hipóteses explicativas e desenvolver uma atitude de questionamento diante de problemas provocados pela globalização e pelo consumo excessivo dos combustíveis fósseis. 
A atividade 8 contou com o debate do tema gerador EA com o foco na reflexão sobre a reciclagem, lixo e recursos naturais. A atividade foi iniciada com a leitura compartilhada do texto "O lixo é um luxo". Posteriormente, o docente problematizou a temática e propôs a realização de alguns exercícios que levassem o aluno a refletir sobre como a coleta seletiva auxilia na preservação dos recursos naturais.

\section{Considerações Finais}

Os resultados evidenciaram que o minicurso contribui para a percepção do professor quanto a importância da EA e para a compreensão que ela pode transpassar todas as disciplinas. Atribuímos esse resultado a forma como 0 mincurso foi planejado e aplicado, ou seja, com lisura e transparência para que os professores tivessem vozes e opiniões garantidas como parte de um processo de sua formação em EA e não apenas como constatação de um problema na escola.

Utilizar as reuniões do ATPCs garantiu a participação dos docentes nas discussões e no planejamento de suas ações, pois são reuniões realizadas no ambiente escolar e dentro da jornada de trabalho, garantindo assim que os professores e a equipe gestora conseguissem debater suas concepções. Dessa forma, aquele docente que inicialmente não participou do debate, por estar com seus pares fica constrangido em não participar e quando todos ficam motivados o trabalho flui de forma diferente, envolvendo o aluno e modificando o ambiente e o formato das aulas.

\section{Referências}

ADAMS, B.G. A importância da lei 9.795/99 e das diretrizes curriculares nacionais da Educação Ambiental para docentes. Revista Monografias Ambientais. Santa Maria, v.10, n.10, p. 2148 - 2157, out./dez., 2012.

AZANHA, J. M. P. Uma reflexão sobre a formação do professor da escola básica. Educação e Pesquisa. São Paulo, v.30, n.2, p.369-378, 2004.

BRASIL. Secretaria da Educação Fundamental. Parâmetros Curriculares Nacionais: Temas Transversais-Meio Ambiente. Brasília: MEC/SEF.1997.

BRASIL. Secretaria de Educação Fundamental. Parâmetros Curriculares Nacionais: Temas Transversais - Meio Ambiente. Brasília: MEC/SEF. 1998.

BRASIL. Lei no 9.795, de 27 de abril de 1999. Política Nacional de Educação Ambiental. Diário Oficial da União. Brasília, DF.1999.

BRASIL. Ministério da Educação. Resolução CNE/CEB 4/2010. Diário Oficial da União, Brasília, 14 de julho de 2010, Seção 1, p. 824, 2010.

CARVALHO, I.C.M. Educação Ambiental e movimentos sociais: elementos para uma história política do campo ambiental. Educação: teoria e prática, São Paulo, v.9, n.16, p.46-56, jan./jun., 2001. 
CUNHA, N.B., CUNHA, M.C., CUNHA, T.N.B. Geração digital- transformação pedagógica. Cadernos da Fucamp, Minas Gerais, v.14, n.20, p.74-83, 2015.

FAHT, E.C. Diagnóstico e análises das atividades relacionadas à Educação Ambiental em escolas públicas de São Paulo -SP e Blumenau-SC. 2011, $130 f$. Dissertação de Mestrado (Ensino de Ciências), Universidade de São Paulo. São Paulo. 2011.

GADOTTI, M. A Carta da Terra na educação. São Paulo: Editora Livraria Instituto Paulo Freire. 2010.

LIPAI, E.M., LAYRARGUES, P.P., PEDRO, V.V. Educação Ambiental na escola: tá na lei. In: RACHEL, S.S.M (Coord.). Vamos cuidar do Brasil: conceitos e práticas em Educação Ambiental na escola. Brasília: Ministério da Educação. UNESCO, 2007, p.23-32.

MEDINA, N.M. A formação dos professores em Educação Ambiental: panorama da Educação Ambiental no Ensino Fundamental. Brasília: MEC; SEF. 2001.

MELLO, A. S., MONTES, S.R., LIMA, L. Educação Ambiental em curso de formação continuada para docentes do ensino básico - Uberlândia (MG). Em extensão, Uberlandia, v.8, n. 1, p.48 - 59. jan./jul., 2009.

MENDONÇA, P.R. Políticas de formação continuada de professores e professoras em Educação Ambiental no Ministério da Educação. In: RACHEL, S.S. (Coord.). Vamos cuidar do Brasil: conceitos e práticas em Educação Ambiental na escola. Brasília: Ministério da Educação. UNESCO, 2007. p.4553. Disponível em: https://unesdoc.unesco.org/ark:/48223/pf0000183079. Acesso: 19 ago 2019.

MIWA, J. Oceanos vão ter mais plástico do que peixe em 2050, diz estudo. 2016. Disponível em: https://thegreenestpost.com/oceano-podera-ter-maisplastico-que-peixes-estudo-revela/. Acesso: 22 ago 2019.

OLIVEIRA, T.M.R. Proposta de minicurso para a formação continuada de professores em educação ambiental. 2018, 143f. Dissertação (Mestrado em Ensino de Ciências e Matemática), Universidade Cruzeiro do Sul. São Paulo, 2018.

PEREIRA, B.T., FREITAS, M.C.D. O uso das tecnologias da informação e comunicação resultando em efetivas práticas pedagógicas na escola. 2009. Disponível em: <http://www.diaadiaeducacao.pr.gov.br/portals/pde/arquivos/1381-8.pdf>. Acesso: 21 ago 2019.

SANTOS, A.G., SANTOS, A.P. A inserção da Educação Ambiental no currículo escolar. Revista Monografias Ambientais, Santa Maria, v.15, n.1, p. 369-380, jan./abr., 2016.

SANTOS, S.A.M. Reflexões sobre o panorama da Educação Ambiental no ensino formal: panorama da Educação Ambiental no Ensino Fundamental. Brasília: MEC/SEF. 2001. 
SORRENTINO, M. De Tbilisi a Thessaloníki: A Educação Ambiental no Brasil. In: QUINTAS, J.S. (org.). Pensando e praticando a Educação Ambiental na gestão do meio ambiente, 3ed. Brasília: Ibama, 2006.

VALDUGA, M., DAL-FARRA, R.A. Formação Docente Continuada e Educação Ambiental: construindo práticas compartilhadas. In: VIII Encontro Nacional de Pesquisa em Educação em Ciências, Campinas, SP, 8, 2011. Anais.......Campinas, $2011 . \quad$ Disponível em: http://www.nutes.ufri.br/abrapec/viiienpec/resumos/R0868-3.pdf. Acesso: 28 ago 2019. 